\title{
The Method of Mission Planning System Verification
}

\author{
Ming Cheng ${ }^{1}$, Yong Song ${ }^{1}$,Yuhan Chen ${ }^{2, *}$ \\ ${ }^{1}$ Naval War Gaming Center, Navy Command College, Nanjing, China \\ ${ }^{2}$ The 28th Research Institute, China Electronics Technology Group Corporation, Nanjing, China \\ ${ }^{*}$ Corresponding author
}

\begin{abstract}
For the needs of developing mission planning system, all levels of mission planning system from home and abroad are studied and analyzed, such as the main functions and applications at the operating environment, ways of working, content, deployment and other ways. Finally, starting from the system development and application environment, propose the method of developing mission planning system. It pointed out that the method of verification mission planning system can be divided into hardware verification, software testing and system level testing. These methods provide reference for the development of mission planning system.
\end{abstract}

Keywords-mission planning system; verification; system test; performance assessment

\section{INTRODUCTION}

Mission Planning System is a set of systems. It contains sensor systems, weapons system, operational planning as one of the operational decision support system, involving guidance and control, geographic information, artificial intelligence, operational regulations and operational logistics and other fields and disciplines. It is the core components of command and control system.

The earliest mission planning system was developed for cruise missile weapon system. Due to the complexity of the mission planning, as well as weak professional and technical basis, which was mainly concerned with their own weapons and route planning, plan attacks. It was very far to provide truly requirements for operational decision support. The current verification of mission planning systems are some of the necessary interface verification, performance verification and validation environment, accompanied with the process of system development [1]. With the subsequent development, and the mission planning system continues to be improved, also the validation method mission planning system requires ongoing research. Verification mission planning system is an important task in the process of development. Mission planning system involves both the performance of weapon systems and the use of combat weapons systems, many functions. So the method of verification mission planning system has many aspects.

In this paper, base on the study of various types of mission planning system at home and abroad, especially in the US military mission planning system. Divided the all mission planning system to several levels, finally, according to the functional content, operational environment and other factors of each level. The verification content and method are analyzed in a detailed way.

\section{Mission Planning System OVERVIEWS}

The research of mission planning in the United States, Britain and other countries is earlier, so the United States as the representative has already entered the practical phase. US equipment and mission planning system was first used in the US Air Force, Navy and Army were also follow-up to develop and equip their own mission planning system.

United States Air Force has focused on the development of top-level mission planning systems and tactical mission planning system since the late 1980s. Upper mission planning system is a tactical expert mission planning system (TEMPLAR) previously used by the US Air Force, the corps level Mission Planning System (FLAPS) and later advanced mission planning system (APS). Upper level joint mission planning system which is for the branches level mission planning system, usually equipped with tactical and strategic Air Command. Air Force Mission Support System (AFMSS), provide automated mission planning support for the Air Force aircraft and airborne weapons systems. AFMSS can be used as a standalone system, but also with other information system for coupling to use. The US Air Force also for different types of aircraft are equipped with mission planning system, such as B1/B-2 / B-52 bombers, F-15/F-16 three generations of machines, F-22/F-35 four generations of machines etc; for airborne precision weapons or special tasks with a special mission planning system, such as the small diameter bomb mission planning system, joint precision airdrop mission planning system (joint precision airdrop Delivery system, JPADS), etc.

Navy tactical aircraft mission planning systems for aviation combat equipment, the system set up in the carrier battle group command center or land bases, can support a variety of fixedwing aircraft, rotorcraft and standoff missiles. US Navy fleet command ship still, aircraft, ships and other Assault landing ship equipped with a maritime planning system (APS) AN/SWQ-1 (V).

Army mission planning systems developed in recent years mainly "net fire" mission planning system, which includes patrol and attack people in planning capacity-loop control is an important part of the Army's combat system.

The US military has focused on research of Military Joint Mission Planning System. Navy and Air Force are codeveloped by the Joint Mission Planning System JMPS and mission planning system based on Digital Earth. JMPS is a collaborative software system development effort between the Air Force and Navy, aimed at achieving centralized mission planning across military. In the system described above can be established C4ISR combat system, using powerful computer 
networks, communications systems and distributed over a wide area, the chain of command, detection devices and a variety of weapons systems to connect together, realizes battlefield sharing, integration from satellites, reconnaissance aircraft, AWACS and other aircraft, surface ships, submarines and ground reconnaissance units provide a variety of high-precision targeting information worldwide, and to provide real-time planning personnel on digital Earth based planning platform for mission planning and emergency modify the task to meet the United States' strategic concept of "global delivery, long-range precision strike".

American Tomahawk cruise missiles mission planning systems, mission support systems in the Air Force since the 1990s of the previous Gulf War, the Kosovo War and the war on terror in Afghanistan have been a real test and fully applied, in which the mission planning played an important role, and had a tremendous military benefits.

Comprehensive analysis of the United States Mission Planning System [2] can be seen:

(1) In the US military C4ISR systems, mission planning system is a fully functional operational decision support system, from multiple levels of operational use to provide support, is a core component of C4ISR.

(2) US military mission planning system level division is very clear, from the top mission planning system to tactical mission planning system and then to a variety of weapons and special mission planning systems, structured, high and low, can actually solve the problem at all levels of combat missions planning.

(3) US emphasis on joint operations, give full play to the Operational Effectiveness of Weapon integrated system, from the early planning and development of a single weapon to weapon for more integrated planning, as well as multi-platform, multi-joint planning of weapons. US are now moving to multibranch system of coordinated combat.

\section{Classification OF Mission PlanNing}

According to the current Mission Planning System function and future development trend of mission planning, mission planning systems can be divided as: operating environment, ways of working, planning content and deployment ways. As shown in Figure I.

\section{A. Operating Environment}

According to the operating environment, Mission planning system can be divided into the ground mission planning systems and weapons platform mission planning system. Ground mission planning system runs in the room, fixed environment, and rich information resources, computing and powerful, mainly for operational-level planning and research. Platform mission planning runs on the sports platform, aircraft, vehicles, unmanned aerial vehicles or missiles. Platform mission planning major changes in the local environment of the battlefield need to quickly deal with, but this time due to the sources of information and transmission of information cannot flow and other reasons, the ground fixing system unusable. Platform mission planning is based on a ground mission planning system, according to local adjustment battlefield situation changes. Platform mission planning system is limited by the working environment that is, less computer resources, work environment requires strictly, and highly demand for the ability to respond quickly.

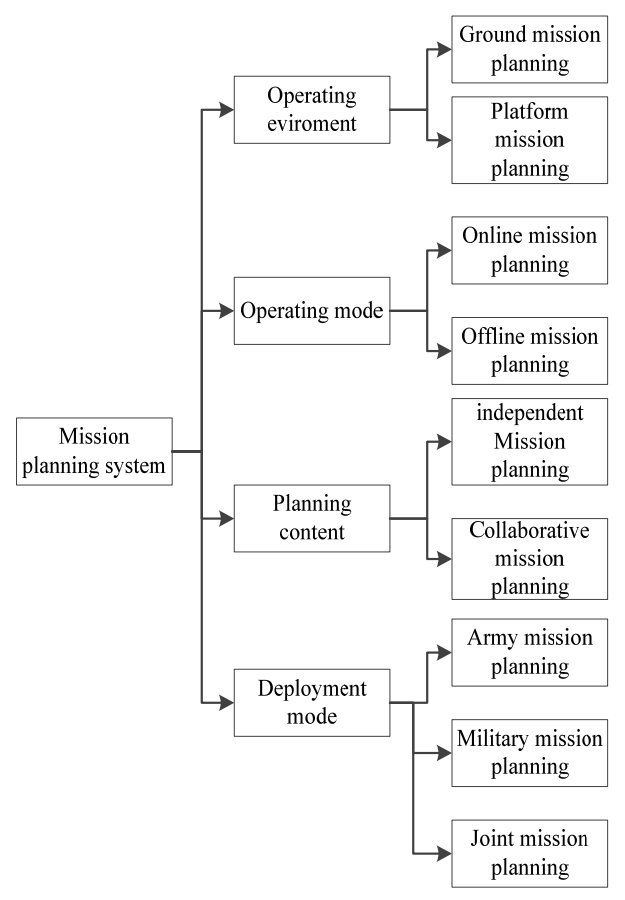

FIGURE I. CLASSIFICATOIN OF MISSION PLANNING SYSTEM

\section{B. Operating Mode}

According to the operating mode, mission Planning System can be divided into online and offline mission planning. Online task is to respond to change in planning requirements of the battlefield situation in real-time planning. Online mission planning are mainly platform mission planning. In the case of battlefield data link is well, ground mission planning is also available for real-time planning for the changing battlefield environment, the planning results upload via data link to the weapons. Offline is basic mission planning, pre-war planning or planning before launching.

\section{Planning Content}

According to planning content, Mission Planning System can be divided into independent mission planning and collaborative mission planning. Independent Mission Planning is to mainly solve a certain type of platform operational track planning and attack task planning, such as missiles, unmanned aerial vehicles and so on. The Task involves many weapons (such as multi-platform operations, multiple command posts, etc.) at the same time planning, it is called collaborative planning.

\section{Deployment Mode}

According to deployment mode, Mission planning system is divided into: arms mission planning, military mission planning and Joint Mission Planning. If the mission planning 
system deployed in a combat troops, combat troops to complete mission planning equipment, called arms Mission Planning. This level of planning is mainly a variety of weapons technology planning and fire planning. If the mission planning system deployment command in the military services a complete multi-type weapons, multiple offensive and defensive forces coordinated the mission planning system level called military Mission Planning. Military Mission planning primarily coordinates the deployment of the various branches of the military offensive, defensive and so on. If the mission planning system is coordinated strike, it is the Joint Mission Planning. Mission planning and military joint mission planning two deployment methods is basically a ground mission planning system.

\section{Method OF SYStem Verification}

Mission Planning System is essentially a sophisticated computer hardware and software systems, where software is the core part of the system. Thus, for verification mission planning system, it can be divided into hardware testing, software testing, and system level test.

Hardware test is related to the classification of mission planning system. For ground mission planning systems, hardware can be used on the market, computer hardware and software products is more mature, hardware and operating environment is in the room and other more relaxed environment. It need not basic hardware tests, only need purchase hardware products for meeting the requirements; platform for mission planning, such as vehicle, airborne, mobile and other platforms. It is necessary to test based on operating platform environmental requirements, including high and low temperature test, shock and vibration test, electromagnetic compatibility test, etc.

For verification mission planning system software components, follow the software engineering thought, software testing is present in all stages of design. Software testing is to ensure software correctness and important part. It is to ensure that the quality of a piece of software an important means and methods. The design process of software testing follows a model shown in Figure II. Mission planning software developed by the " $\mathrm{V}$ " model, design focusing on the left, the right side of focusing on verification.

Mission Planning system-level verification can be divided into: functional verification, performance verification, system software testing, hardware-software testing, external interface verification, platform test, flight test, battlefield simulation, military trial.

\section{A. Content of Verification}

\section{1) Functional verification}

Functional verification is to verify whether the mission planning system meets the design requirements. Design requirements, including demand planning function, user requirements and operational use requirements. These design requirements in mission planning should have proposed in the functional form, it needs to be verified [3].

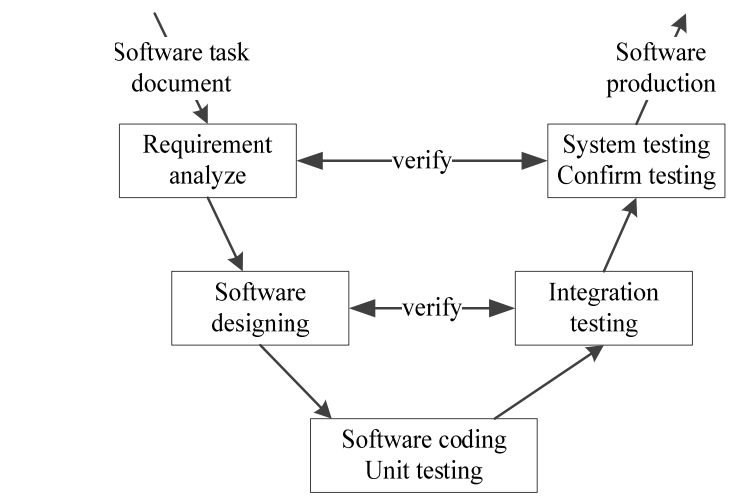

FIGURE II. TEST MODELS IN DEFERENT PHASES OF SOFTWARE DEVELOPMENT

\section{2) Performance verification}

The mission planning system performance is Closely related to and planning battlefield environment, the hardware platform, the guidance system complexity and planning methods, especially in the battlefield environment, related to geographic information, the enemy defense deployment information, one's own tactical intentions and so on. Therefore, the mission planning system performance, especially at certain times of the performance indicators are often in the form of statistical average time metrics concepts presented. Mission Planning System performance verification is one of importantly verification contents [4].

Performance verification is related with system-related hardware environment. Therefore, the performance verification system requires the delivery in the actual use environment. For platform mission planning systems, especially airborne and onboard mission planning, the main performance verification required by mathematical simulation, and semi-physical simulation and flight tests verified.

\section{3) Software testing}

Mission planning system involves battlefield information processing, target analysis, trajectory (path) planning, planning attacks, and war games and so on, it is a large, complex systems. Whether from the system functional or software the architecture, mission planning systems need to be divided into some functional structural components (or member). Thus, the interface coordination between the mission planning software, the correctness of the process and so on, needs to be verified by the testing between software. Moreover, to test such software systems, it is necessary between mission planning software between the two systems.

\section{4) Software-hardware testing}

There are significant differences between Mission planning system developed environment and the final operating environment. Developed environment generally is higher computer performance, relaxed working environment, and aid in the development of complex environment than operating environment. Therefore, the mission planning software can run smoothly in the final operational environment, the softwarehardware testing needs to be validated by the final status 
between hardware and software. Moreover, the performance verification system also needs to be verified in this final environment.

\section{5) external interface verification}

Under normal circumstances, the ground mission planning system as a combat command and decision system, auxiliary systems exist independently, so the ground mission planning system is the direct interface to the external command system. But the ground mission planning system and other systems there is a strong link indirectly. A lot of data from the mission planning system to the support system, mission planning outcomes such as track to be uploaded to the respective operational entities, and so on, these interfaces will need to be verified. If the ground mission planning system involves collaborative planning or joint planning between the various interfaces many weapons also must be verified.

Platform mission planning system external interfaces is deferent with ground mission planning systems. Its interface information from the location information platform, data link instruction information transmission, detection information, such information is mostly dynamic information. Therefore, the verification platform mission planning system can be done through the semi-physical simulation platform tests.

\section{6) Platform testing}

For platform mission planning systems, mission planning system could become one of the most key targets. The main purpose of the test is to verify platform in movement conditions, mission planning systems for battlefield between the work environment adaptability, performance verification, as well as other systems and platforms of coordination

\section{7) Flight testing}

Flight test is important test functions for verification the systems on aircraft and aircraft-related systems, processes, algorithms correctness, as well as coordination of the interface. Mission planning as an important subsystem of weapon systems, mission planning flight test can verify the results of the planning accuracy, correctness of the planning process, mission planning system interfaces with other subsystems coordination, etc.

\section{8) Battlefield simulation}

Battlefield simulation is an important way to comprehensive verify mission planning system. Battlefield simulation can simulate combat conditions near reality, set the two sides of the offensive and defensive deployment environment, complete the planning by the mission planning system; the final evaluation is given by way of assessment, in order to fully verify the functionality and performance of mission planning system. Battlefield simulation verification mission planning for military and joint mission planning is particularly important.

\section{9) Military trial}

Military trial is based in terms of the eventual use of weapons and equipment to mission planning system functionality, performance, inspection and verification.
Military trial can check the final system fully functional, system ease of use.

\section{B. Method of Verification}

In addition to flight testing, test platform, the other verification methods are to design a variety of scenarios, according to the system-defined workflow using a job or emulation mode on the map, planning the outcomes. By results of correctness, correctness running processes to determine whether the test results met the demand.

Test scenarios, including basic data scenarios, such as terrain elevation data, image data, and so on, but also include battlefield data, including the two sides of the tactical intent, etc [5].

\section{CONCLUSION}

Mission Planning System is a large and complex computer hardware and software systems, including both single-platform weapon planning and collaborative planning involving various weapons systems, while closely related to the operational applications and smart decisions. Mission planning system verification is the important part. Since the relevant foreign mission planning system disclosed less information reasons, the system verification method is rare. Based on many years of development work, there works on the mission planning system is to verify a preliminary summary of technology, to provide reference for the development of mission planning systems.

\section{REFERENCES}

[1] LIU Xin- yan, HU AN G Xian-lin,WU Qiang.The Review on the Development of Mission Planning System in Foreign Countries[J].Fire Control and Command Control, 2007(6).

[2] Zheng C, Li L, Xu F, et al.Evolutionary route planner for unmanned air vehicles[J].IEEE Transactions on Robotics, 2005.

[3] Deng xiao-ni. Research on the Validatioin Methods of the C4ISR System requirements Based on Model Checking and Simulation[D].National University of Defense Technology, 2008.

[4] LI He,LV Yan,YANG Ming-quan. Vlidation of Flight Simulator's Flight Performance Based on Spectrum Analysis. JOURNAL OF ORDNANCE ENGINEERING COLLEGE.2008,20(6).

[5] ZHU MingBIAN, Ji-nianWU, Wei-min. Collaborative verification scheme for system functional properties. COMPUTER INTEGRATED MANUFACTURING SYSTEMS,CIMS.2005. 11(12). 